\title{
Synthesis, characterization, and antibacterial activities of some metal complexes with tripodal Schiff base ligand derived from pyrrole-2- carboxaldehyde
}

\author{
Fatemeh Dashti Rahmatabadi |Roya Ranjineh Khojasteh* |Hassan Kabiri Fard |Fariba Tadayon
}

Department of Inorganic Chemistry, Faculty of Chemistry, Tehran North Branch, Islamic Azad University, 1651153311, Tehran, Iran

\section{*Corresponding Author:}

Roya Ranjineh Khojasteh

Email: r_ranjinehkhojasteh@iau-tnb.ac.ir Tel.: +98 (21) 77317998

The tripodalheptadentate Schiff base ligand, $\mathrm{C}_{21} \mathrm{H}_{27} \mathrm{~N}_{7}$, was derived from pyrrole-2-carboxaldehyde with tris(2aminoethyl)amine (tren) and its complexes with Cd(II), Co(II), Mn(II) and Ni(II) metal ions have been synthesized. The Schiff base and its metal complexes have been identified by IR, UV-Vis, ${ }^{1} \mathrm{H}-\mathrm{NMR},{ }^{13} \mathrm{C}$-NMR spectroscopy, elemental analysis and thermo gravimetric analysis (TGA). According to the spectroscopic and elemental analyses data, it was found that the Schiff base was coordinated to the metal ions as a potentially heptadentate ligand. All compounds showed antibacterial properties against the gram-positive bacteria; Bacillus cereus, Staphylococcus aureus, and gram-negative bacteria; Pseudomonas aeruginosa, Escherichia coli by using disc diffusion and micro-broth dilution methods. Also, the metal complexes showed a greater inhibitory effect than their individual ligand. Bacillus cereus was the most susceptible bacterial species to Co(II) complex while Escherichia coli required a relatively higher minimum inhibition concentration of Mn(II) complex.

\section{KEYWORDS}

Pyrrole-2-carboxaldehyde; Schiff base complexes; polydentate ligand; antibacterial activities; thermo gravimetric analysis.

\section{Introduction}

Inorganic elements play a major role in biological processes [1]. Schiff base acts as a polydentate ligand and it is usually coordinated through the nitrogen atom of the azomethine group [2]. Stable Schiff bases are formed by aromatic aldehydes with an effective conjugate system [3]. There are few studies of Schiff base complexes involving ligands having seven potential donor atoms. In general, studies of heptadentatetripodal Schiff base ligands are derived from tris(2aminoethyl)amine (tren) and various rings substituted with pyridine or thiophencarboxaldehyde, salicylaldehydes and hydroxyacetophenone [4-14]. Tris (2aminoethyl) amine is used as a scaffold for the preparation of tripodal ligands [15-16]. Now, there is a little information available about the coordination chemistry of the potentially heptadentate $\left(\mathrm{N}_{7}\right)$ ligand.

As far as we are aware, synthesis of potentially heptadentate $\left(\mathrm{N}_{7}\right)$ ligand derived from condensation reactions of tris(2aminoethyl) amine (tren) with pyrrole-2carboxaldehyde, have been reported by Wang et al. [17] and its coordination compound with $\mathrm{Fe}^{+3}$ was synthesized by Sinn et al. [18]. Synthesis of similar types of ligands with the $\mathrm{N}_{7}$ complexation sphere with $\mathrm{V}^{4+}$ was investigated by Yilmaz [19]. The applications of macrocyclic Schiff bases include contrast agents in magnetic resonance imaging (MRI) [20], radiopharmaceuticals [21] and catalytic cleavage of RNA [22]. 
In this paper, we introduce a novel method for the synthesis of the tripodalheptadentate ligand, $\mathrm{C}_{21} \mathrm{H}_{27} \mathrm{~N}_{7}$ and achieve high purity and yield in less time. The Schiff base ligand and $\mathrm{Co}(\mathrm{II}), \mathrm{Ni}(\mathrm{II}), \mathrm{Cd}(\mathrm{II})$ and $\mathrm{Mn}(\mathrm{II})$ complexes were synthesized and characterized by fourier transform infrared spectroscopy (FTIR), proton and carbon nuclear magnetic resonance $\left({ }^{1} \mathrm{H}-,{ }^{13} \mathrm{C}-\mathrm{NMR}\right)$, ultraviolet-visible (UV-Vis), elemental analysis and thermo gravimetric analysis (TGA). The Schiff base compounds were assessed for antibacterial activities against Escherichia coli, Pseudomonas aeruginosa, Bacillus cereus and Staphylococcus aureus.

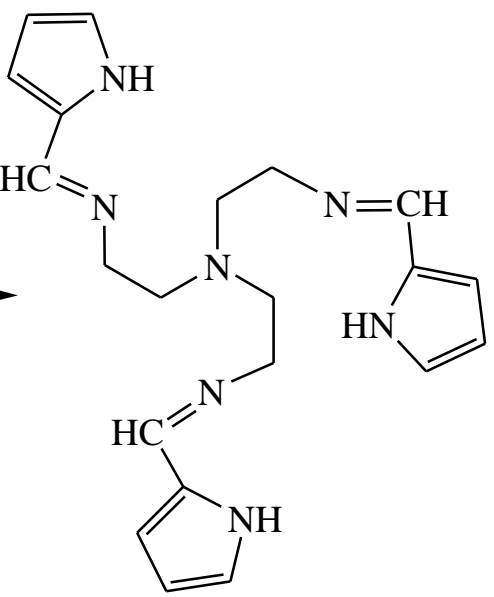

FIGURE 1 Synthesis of the ligand (Tris[2-(pyrrol-2-ylmethyl-eneamino)ethyl] amine)

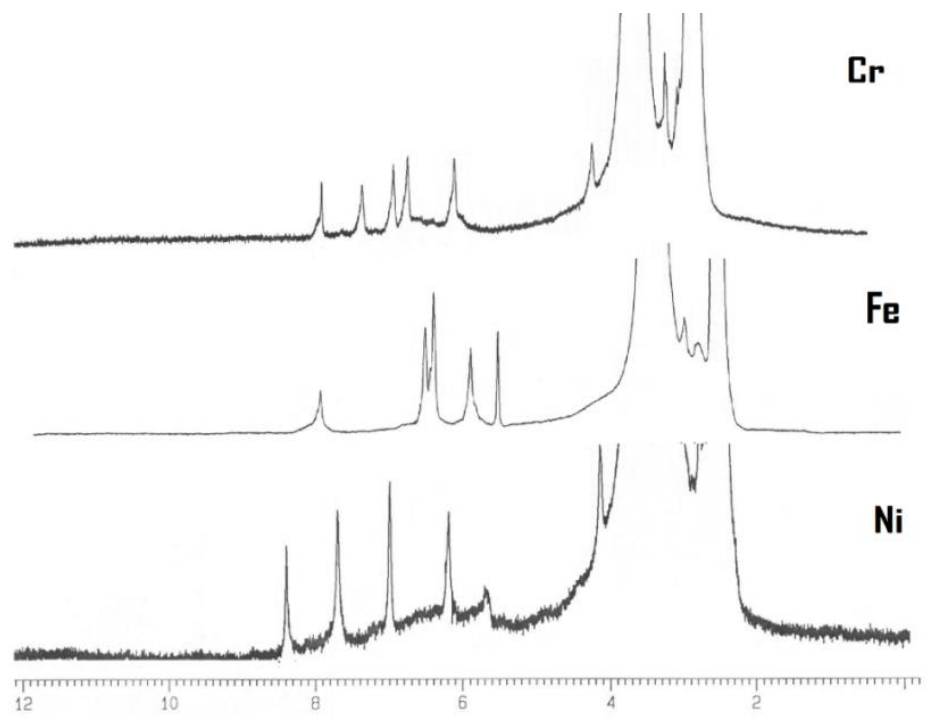

FIGURE $2{ }^{1} \mathrm{H}$ NMR spectrum of Schiff base complexes 


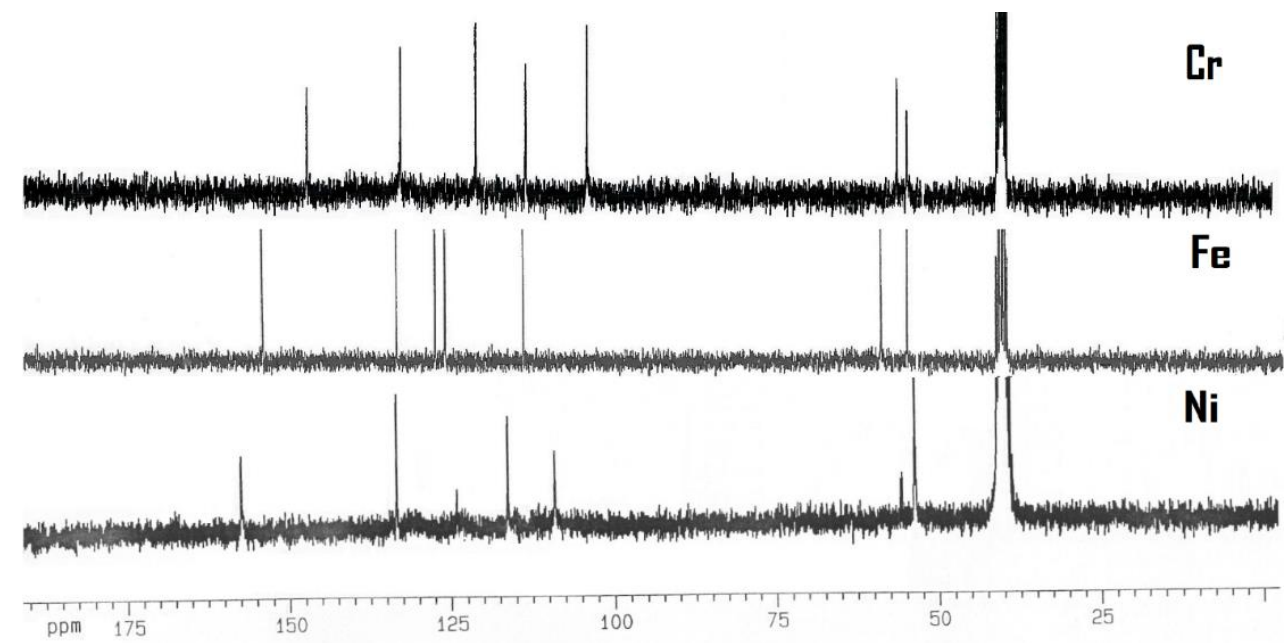

FIGURE $3{ }^{13} \mathrm{C}$ NMR spectra of Schiff base complexes

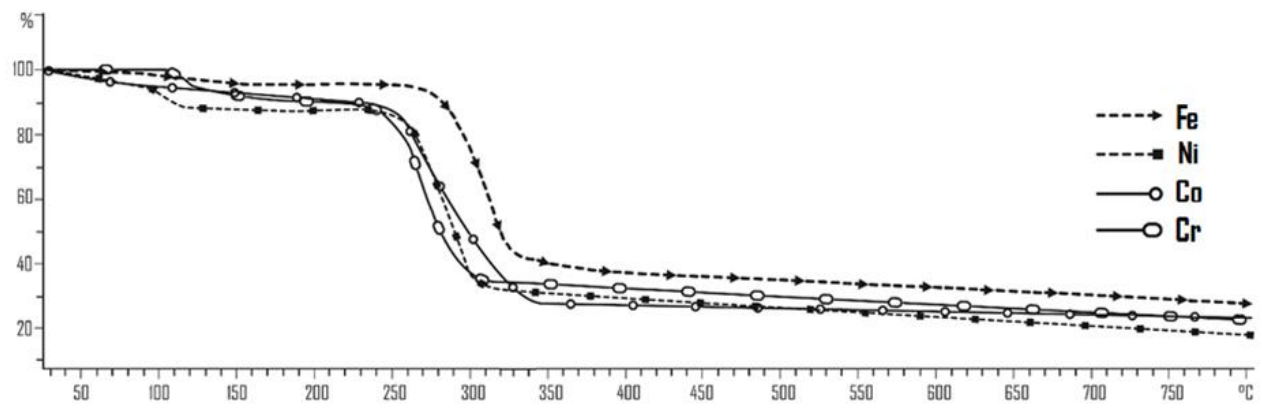

FIGURE 4 TGA curves of Schiff base complexes

\section{Experimental}

\section{General}

Tris(2-aminoethyl)amine (tren) and pyrrole2-carboxaldehyde and other chemicals used in this study were obtained from SigmaAldrich and Merck Companies. Thin-Layer chromatography (TLC) was performed using n-hexane/EtOAC (1:3) as an eluent. The UVVis spectra were recorded on a varian Cary 100 spectrophotometer in DMSO. The Fourier-transform infrared spectroscopy (FTIR) spectra were recorded using on Shimidzo 300 spectrometer $\mathrm{KBr}$ pellets. NMR spectra $\left({ }^{1} \mathrm{H}-,{ }^{13} \mathrm{C} \mathrm{NMR}\right)$ were acquired in $\mathrm{DMSO}^{-\mathrm{d}_{6}}$ solution using Brucker AMX $250 \mathrm{MHz}$ spectrometer with tetramethylsilane (TMS) as internal standard for ${ }^{1} \mathrm{H}$ NMR analysis. Melting points of the synthesis compounds were obtained from electrothermal type 9100 capillary melting point apparatus. The elemental analysis of the samples was performed on PerkinElmer elemental analyzer. The thermo gravimetric analysis (TGA) were carried out in a dynamic nitrogen atmosphere (20 mL.min $\left.{ }^{-1}\right)$, with a heating rate of $10^{\circ} \mathrm{C} \mathrm{min}-1$ using Shimadzu TGA-50H thermal analyzers. Isolates of bacteria were purchased from Persian Type Culture Collection (PTCC).

\section{Synthesis of Schiff base ligand}

Tris (2-amino ethyl)amine $(6.84 \mathrm{mmol}$, in 20 $\mathrm{mL}$ methanol) was added dropwise to a solution of pyrrole-2-carboxaldehyde (20.5 mmol, in $10 \mathrm{~mL}$ DMSO). The solution was stirred at room temperature overnight. Then, reaction mixture was cooled in an ice bath for 30 min and washed with diethyl ether and dried in vacuum and then recrystallized in 
hot ethanol. After evaporation of the solvent, the product was obtained.

Orange solid, Yield: (75\%); $\mathrm{mp}=122-125$ ${ }^{\circ} \mathrm{C}$, IR data $\left(\mathrm{v}, \mathrm{cm}^{-1}\right): 3128.90(\mathrm{~N}-\mathrm{H}), 2939.70$ (C-H) aliphatic, $3084.84 \quad\left(\mathrm{CH}_{2}\right), \quad 1641.09$ $(\mathrm{C}=\mathrm{N}), \quad 1169.76 \quad(\mathrm{C}-\mathrm{N}), \quad 1554.72 \quad(\mathrm{C}=\mathrm{C})$, $1032.41(\mathrm{~N}-\mathrm{H})$. UV-VIS (DMSO): $\lambda \max =286$, 207, 204 nm. ${ }^{1} \mathrm{H}$ NMR (ppm d d $\left.^{-D M S O}\right) \delta: 2.75$ $(\mathrm{t}, 6 \mathrm{H}), 3.51(\mathrm{t}, 6 \mathrm{H}), 6.07(\mathrm{mu}, 3 \mathrm{H}, \mathrm{Ar} \mathrm{H}), 6.32$ (d-d, 3H, Ar H), 6.82 (s, 3H,Ar H), 7.95 (s, $\mathrm{HC}=\mathrm{N}, 3 \mathrm{H}$ ), $11.30(\mathrm{~s}, 3 \mathrm{H}, \mathrm{NH}) ;{ }^{13} \mathrm{C}-\mathrm{NMR}$ : (ppm $\mathrm{d}_{6}$-DMSO): 55.50, 58.88, 108.71, 113.22, 121.86, 130.13, 152.38. Calculated for $\mathrm{C}_{21} \mathrm{H}_{27} \mathrm{~N}_{7} \%$ : C 64.28, H 9.18, N 12.28. Found, \% C 64.02, H 9.12, N 12.13.

\section{Complexes synthesis}

All of the complexes were readily prepared by addition of ligand (1mmol in $10 \mathrm{~mL}$ methanol) to a solution of the metal chloride (1 mmol in the same solvent). The ligand (1 $1 \mathrm{mmol}$ ) was dissolved in $10 \mathrm{~mL}$ of methanol and the solution was stirred for $30 \mathrm{~min}$ at room temperature. The metal salt $(1 \mathrm{mmol})$ was dissolved in $5 \mathrm{~mL}$ ethanol; then, the solution was added to the ligand solution and stirred with heating for $4 \mathrm{~h}$. Finally, solution of $\mathrm{NaOH}(0.12 \mathrm{~g}, 3 \mathrm{mmol})$ in absolute ethanol ( $3 \mathrm{~mL}$ ) was added. The color of the complexes changed at first. The resulting mixture was boiled under reflux for 7-8 $\mathrm{h}$. The progress of the reaction was checked with TLC. Finally, the precipitate of the complex was recovered by filtration, washed with ether and dried in a vacuum.

Cadmium Complex: Dark gray solid; Yield: (68\%); $\mathrm{mp}=252-255^{\circ} \mathrm{C}$, IR data $\left(\mathrm{v}, \mathrm{cm}^{-}\right.$ 1): $3450.90(\mathrm{~N}-\mathrm{H}), 2920.06(\mathrm{C}-\mathrm{H})$ aliphatic, $3156.22\left(\mathrm{CH}_{2}\right), 1629.55(\mathrm{C}=\mathrm{N}), 1190.38(\mathrm{C}-\mathrm{N})$, 1441.37 (C=C), $1033.38(\mathrm{~N}-\mathrm{H}), 481.38(\mathrm{M}-$ N).UV-VIS (DMSO): $\lambda \max =432,320,311 \mathrm{~nm}$, ${ }^{1} \mathrm{H}$ NMR (ppm d ${ }_{6}$-DMSO) $\delta: 2.84(\mathrm{t}, 6 \mathrm{H}), 3.89$ $(\mathrm{t}, 6 \mathrm{H}), 6.13$ (mu, 3H, Ar H), 6.85 (d-d, 3H, Ar H), 7.06 (s, 3H, Ar H), 7.54 (s, HC=N, 3H), 8.16 (s, 3H, NH); ${ }^{13} \mathrm{C}$ NMR: (ppm d 6 -DMSO): 55.55, 57.86, 106.30, 117.09, 125.79, 138.45,
153.62. Calculated for $\mathrm{Cd}_{21} \mathrm{H}_{27} \mathrm{~N}_{7} \%$ : C 64.28, H 9.18, N 12.28. Found, \% C 64.02, H 9.12, N 12.13

Nickel complex: Green solid; Yield: (80\%); mp =286-290 으, IR data $\left(\mathrm{v}, \mathrm{cm}^{-1}\right)$ : $3423.44(\mathrm{~N}-\mathrm{H}), \quad 2962.14 \quad(\mathrm{C}-\mathrm{H})$ aliphatic, $3281.01\left(\mathrm{CH}_{2}\right), 1632.80(\mathrm{C}=\mathrm{N}), 1133.13(\mathrm{C}-\mathrm{N})$, $1384.10 \quad(\mathrm{C}=\mathrm{C}), 1031.63(\mathrm{~N}-\mathrm{H}), 485.25(\mathrm{M}-$ N).UV-VIS (DMSO): $\lambda \max =624,368,341 .{ }^{1} \mathrm{H}$ NMR (ppm d $\mathrm{d}_{6}$-DMSO) $\delta: 2.87(\mathrm{t}, 6 \mathrm{H}), 4.13(\mathrm{t}$, 6H), 5.69 (mu, 3H, Ar H), 6.13 (d-d, 3H, Ar H), 6.98 (s, 3H, Ar H), 7.69 (s, HC=N, 3H), 8.38 (s, $3 \mathrm{H}, \mathrm{NH}) ;{ }^{13} \mathrm{C}$ NMR: (ppm d 6 -DMSO): 53.84, 56.93, 109.27, 116.14, 124.28, 133.61, 157.34. Calculated for $\mathrm{Ni}_{21} \mathrm{H}_{27} \mathrm{~N}_{7} \%$ : C 67.28, H 7.46, N 10.45. Found, \% C 67.13, H 7.40, N 10.39 .

Cobalt complex: Brown solid; Yield: (83\%); $\mathrm{mp}=271-275^{\circ} \mathrm{C}$, IR data $\left(v, \mathrm{~cm}^{-1}\right)$ : $3397.30 \quad(\mathrm{~N}-\mathrm{H}), \quad 2949.47 \quad(\mathrm{C}-\mathrm{H})$ aliphatic, $3130.52\left(\mathrm{CH}_{2}\right), 1596.87(\mathrm{C}=\mathrm{N}), 1109.77(\mathrm{C}-\mathrm{N})$, 1384.36 (C=C), $1050.27(\mathrm{~N}-\mathrm{H}), 477.50$ (MN).UV-VIS (DMSO): $\lambda \max =625,381,300 .{ }^{1} \mathrm{H}$ NMR (ppm d ${ }_{6}$-DMSO) $\delta: 2.89(\mathrm{t}, 6 \mathrm{H}), 3.18(\mathrm{t}$, $6 \mathrm{H}$ ), 5.79 (mu, 3H, Ar H), 6.23 (d-d, 3H, Ar H), 6.65 (s, 3H, Ar H), 6.77 (s, HC=N, 3H), 8.248 (s, 3H, NH); ${ }^{13} \mathrm{C}$ NMR: (ppm d 6 -DMSO): 54.85, 58.70, 116.38, 128.54, 130.27, 136.53, 156.84. Calculated for $\mathrm{Co}_{21} \mathrm{H}_{27} \mathrm{~N}_{7} \%$ : C 70.28, H 8.95, N 11.60. Found, \% C 69.58, H 8.62, N 11.33

Manganese complex: Red - brown solid; Yield: (80\%); M.p. 306-310 ํ․ IR data (KBR, $\left.\mathrm{cm}^{-1}\right)$ : $3419.18(\mathrm{~N}-\mathrm{H}), 2923.91(\mathrm{C}-\mathrm{H})$ aliphatic, $3215.20\left(\mathrm{CH}_{2}\right), 1618.81(\mathrm{C}=\mathrm{N}), 1096.58(\mathrm{C}-\mathrm{N})$, $1585.46(\mathrm{C}=\mathrm{C}), 1036.21(\mathrm{~N}-\mathrm{H}), 528.92(\mathrm{M}-\mathrm{N})$. UV-vis (DMSO): $\lambda \max =408,348,311 \mathrm{~nm} .{ }^{1} \mathrm{H}$ NMR and ${ }^{13} \mathrm{C}$ NMR data were not obtained because the complex was paramagnetic. Calculated for $\mathrm{Mn}_{21} \mathrm{H}_{27} \mathrm{~N}_{7} \%$ C 57.02, H 7.52, N 12.56. Found, \% C 57.08, H 7.42, N 12.43.

\section{Antibacterial study}

All compounds were tested to evaluate their antibacterial activity against Staphylococcus aureus (PTCC: 1112), Bacillus cereus (PTCC: 
1015) as gram-positive bacteria; and Escherichia coli (PTCC: 1330), pseudomonas aeruginosa (PTCC: 1074) as gram negative, by employing two methods: Micro-broth dilution minimum inhibition concentration and disc diffusion [23-24]. The inoculum density of each bacterial isolate was standardized with 0.5 McFarland turbidity standards. The suspension had a final inoculum of 5 $\times 10^{8} \mathrm{cfu} / \mathrm{mL}$ (colony-forming unit).

\section{Disc diffusion method}

The synthesized compounds (20 mg) were dissolved in $1 \mathrm{~mL}$ of dimethyl sulfoxide (DMSO). Microbial inoculums were performed on a sterile molar Hinton agar using a sterile swab. Sterile discs $(6 \mathrm{~mm})$ were placed in the solution of the compounds and then placed on agar plate bacteria. The plates were incubated at $37{ }^{\circ} \mathrm{C}$. After $24 \mathrm{~h}$, the area of inhibition (in $\mathrm{mm}$ ) was measured around the disc. However, standard antibiotics (tetracycline, gentamicin, ampicillin, ciprofloxacin and penicillin) were also evaluated. The disk containing DMSO was also used as a negative control with no inhibitory region observed.

\section{Micro-broth dilution minimum inhibition concentration}

Micro-broth dilution is a technique to determine the Minimum Inhibitory Concentration (MIC), which determines the inhibited growth of bacteria due to the turbidity in the tube. $1 \mathrm{~mL}$ of sterile MullerHinton Broth was added to the 13 sterile tubes. The synthesized compound $(2000$ $\mu \mathrm{g} / \mathrm{mL}$ in DMSO) was added to the first tube. After pipetting, $1 \mathrm{~mL}$ of solution was removed from the first tube and added to the second tube. This process was repeated for all tubes except the tube number 13. Stock solutions were prepared and dilutions were made according to the guidelines in NCCLS. Then, a certain amount of bacterial suspension (0.5 McFarland turbidity standards) was added to all tubes except the tube number 12 (control sample). Finally, the tubes were incubated for $18-24 \mathrm{~h}$ at $37^{\circ} \mathrm{C}$.

\section{Results and discussion}

\section{Physical measurements}

The Schiff base ligand was prepared by the addition of one equivalent of tris(2aminoethyl) amine with 3 equivalents of pyrrole-2-carboxaldehyde in DMSO, as shown in Figure 1. Good yield indicated the correct process of ligand production. The ligand was melted at $122-125{ }^{\circ} \mathrm{C}$ and soluble in organic solvents such as ethanol, methanol, chloroform, etc., but complexes are soluble on DMSO and DMF. The synthesized compounds were produced in high yield and purity according to the ${ }^{1} \mathrm{H}-,{ }^{13} \mathrm{C}-\mathrm{NMR}$ (Figures 2-3) and thin layer chromatography (TLC).

The IR spectra of complexes were compared with the free ligand and displayed in Figure 1. In the IR spectrum of the ligand, the sharp band due to the azomethine $v_{(\mathrm{C}=\mathrm{N})}$ appeared at $1641 \mathrm{~cm}^{-1}$, while the complexes were present in the $1596-1632 \mathrm{~cm}^{-1}$ region. This peak shifted to lower frequencies in the complexes, which indicate the involvement of azomethine nitrogen in the coordination to the metal ions. The band observed at 1554 $\mathrm{cm}^{-1}$ is due to the $\mathrm{C}=\mathrm{C}$ stretching of the aromatic ring system; however, the signal was shifted in the spectra of the metal complexes. Evidence regarding the bonding of the metal centers with the nitrogen atoms of the Schiff base was provided by the appearance of new bands in the $470-520 \mathrm{~cm}^{-1}$ region. A comparative absorption pattern of the complexes with free ligand show the coordination of nitrogen to the central metal ion at $481,485,477$ and $528 \mathrm{~cm}^{-1}$ for the $v_{(\mathrm{M} \text { - }}$ $\mathrm{N})$. Therefore, the IR spectra results provided strong evidence for the complexation of synthesis of ligand and its complexes.

The electronic spectra of the complexes and ligand were recorded in DMSO solution. The ligand showed the absorption bands in 
286, 207 and $204 \mathrm{~nm}$ which are assigned to the $n \rightarrow \pi^{*}$ and $\pi \rightarrow \pi^{*}$, these bands were shifted to some extent, because the imine nitrogen is involved in coordination with the metal ion. The peaks of MLCT transitions for the metal complexes are shifted to higher frequencies. The electronic spectra of the metal complexes have similar properties. The vibrations found below $311 \mathrm{~nm}$ originate from $n \rightarrow \pi^{*}$ transitions associated with the aromatic ring and the absorption in the range of 320-381 nm can be attributed to $\pi \rightarrow \pi^{*}$ transitions of the $\mathrm{C}=\mathrm{N}$ bonds. The bands observed at about 408-625 $\mathrm{nm}$ can be attributed to $\mathrm{d}-\mathrm{d}$ transitions for metal complexes.

The ${ }^{1} \mathrm{H}-\mathrm{NMR}$ and ${ }^{13} \mathrm{C}$-NMR spectra of these products also clearly confirm their purity and formation (Figures 2 and 3). ${ }^{1} \mathrm{H}-\mathrm{NMR}$ spectrum of the ligand showed a peak at 7.95 ppm for $\mathrm{CH}=\mathrm{N}$ (azomethine) group, and in the ${ }^{13} \mathrm{C}$-NMR spectrum of the ligand, the signal due to the azomethine carbon atom appeared at $152.38 \mathrm{ppm}$ which in the complexes were shifted. The aromatic protons signals were assigned between 6.07 and $6.82 \mathrm{ppm}$ for the free ligand and the metal complexes. The $-\mathrm{CH}_{2}$ group signals were observed between 2.75 and $3.51 \mathrm{ppm}$ for the ligand and complexes. These peaks were shifted in the metal complexes which indicated the coordination bond formation. According to ${ }^{13} \mathrm{C}-\mathrm{NMR}$ spectrum of ligand, the peaks obtained at 108-130 ppm for aromatic and signals at 55 and $58 \mathrm{ppm}$ which correspond to the methylene groups. These peaks were shifted in the metal complexes. Azomethine carbon atom was seen at $152 \mathrm{ppm}$ that shifted in the spectra of complexes.

\section{Thermo gravimetric analysis}

Thermal analysis is used to assign the thermal stability of the complexes and its degradation pattern. The heating rates were controlled at $10{ }^{\circ} \mathrm{C} \mathrm{min}^{-1}$ under nitrogen atmosphere and weight loss from ambient temperature was measured to $800{ }^{\circ} \mathrm{C}$. The thermo gravimetric analysis (TGA) curves of the complexes are given in Figure 4.

The TG curves for all the complexes initially showed a weight loss at about $90{ }^{\circ} \mathrm{C}$ $(\sim 5.0 \%)$ indicating the presence of lattice water molecules in the complexes. Weight loss up to $260{ }^{\circ} \mathrm{C}(\sim 57.2 \%)$ indicates a fully degradation of ligand. It was observed at temperatures above $380{ }^{\circ} \mathrm{C}$ that fully organic part of the chelate decomposed and eventually the metal oxide remains. So, the thermal stability of all complexes increases in the order: $\mathrm{Co}>\mathrm{Cd}>\mathrm{Mn}>\mathrm{Ni}$.

\section{Biological activity}

Antibacterial activity of the ligand and its complexes have been carried out against Escherichia coli, Pseudomonas aeruginosa, which represented gram negative bacteria and Bacillus cereus and Staphylococcus aureus, which served as gram positive bacteria, by disk diffusion and micro-broth dilution methods. Tetracycline, Gentamicin, Ampicillin, Ciprofloxacin and Penicillin were used as standard antibiotics. In the antimicrobial sensibility test by disk diffusion (Table1), Mn(II) complex demonstrated the highest antibacterial activity against the Bacillus cereus and $\mathrm{Ni}$ (II) complex was the least active against the Escherichia coli. According to the results in Table 2, antibacterial activity of metal complexes represented against bacteria, respectively: Escherichia coli $(\mathrm{Cd}>\mathrm{Co}>\mathrm{Mn}>\mathrm{Ni})$, pseudomonas aeruginosa $(\mathrm{Cd}>\mathrm{Mn}=\mathrm{Co}>\mathrm{Ni})$, Staphylococcus aureus $(\mathrm{Mn}>\mathrm{Cd}>\mathrm{Co}>\mathrm{Ni})$ and Bacillus cereus $(\mathrm{Mn}>\mathrm{Cd}>\mathrm{Co}>\mathrm{Ni})$. In general, the complexes showed more antibacterial activity than the free ligand. The highest MIC was detected for Mn(II) complex against Bacillus cereus and the lowest was measured for Ni(II) against Escherichia coli. According to the results, complexes have a higher activity than the free ligand. This is due to the larger lipophilic nature of the ions in complexes. Such increased activity of the 
metal chelates can also be explained on the basis of chelating theory [26] and Overtone's concept [27]. According to the chelation theory, the polarity of the metal ion is reduced to a greater extent due to the overlap of the ligand orbital and partial sharing of the positive charge of the metal ion with donor groups. Furthermore, it increases the delocalization of $\pi$-electrons over the whole chelate ring and enhances the lipophilicity of the complex. This increased lipophilicity enhances the penetration of the complexes into lipid membranes and blocking of metal binding sites on the enzymes of the microorganisms [28-29].

TABLE 1 Antibacterial bioassay of ligand and its metal(II) complexes (zone of inhibition in $\mathrm{mm}$ )

\begin{tabular}{ccccc}
\hline Compound & E. Coli & P. Aeruginosa & S. Aureus & B. Cereus \\
\hline Ligand & 10 & 11 & 11 & 12 \\
Co(II) Complex & 12 & 15 & 16 & 25 \\
Cr(II) Complex & 17 & 18 & 14 & 17 \\
Ni(II) Complex & 11 & 12 & 12 & 13 \\
Fe(II) Complex & 14 & 15 & 13 & 14 \\
Tetracycline & 18 & - & 21 & 25 \\
Gentamicin & 20 & 22 & 20 & 23 \\
Ampicillin & - & 10 & - & 11 \\
Ciprofloxacin & 11 & - & 10 & - \\
penicillin & 13 & - & - & 14 \\
DMSO & 0 & 0 & 0 & 0 \\
\hline \hline
\end{tabular}

TABLE 2 Antibacterial MIC of the compounds

\begin{tabular}{ccccc}
\hline Compound & E. Coli & P. Aeruginosa & S. Aureus & B. Cereus \\
\hline Ligand & 20 & 10 & 10 & 5 \\
Co(II) Complex & 5 & 2.5 & 1.25 & 0.62 \\
Cr(II) Complex & 1.25 & 1.25 & 2.5 & 1.25 \\
Ni(II) Complex & 10 & 5 & 5 & 2.5 \\
Fe(II) Complex & 2.5 & 2.5 & 5 & 2.5 \\
\hline
\end{tabular}

complex showed the best activity against

\section{Conclusion}

Tripodalheptadentate Schiff-base ligand derived from condensation reactions of pyrrole-2-carboxaldehyde with tris(2aminoethyl)amine (tren) and its metal complexes were synthesized. The synthesis compounds were characterized using FT-IR, ${ }^{1} \mathrm{H}-\mathrm{NMR},{ }^{13} \mathrm{C}-\mathrm{NMR}, \mathrm{UV}-\mathrm{V}$ is spectra and TGA. A thermal study revealed that the complexes are thermally stable. Based on the results, it was found that the synthesized compounds had antibacterial properties. Of course, the antibacterial property of the complexes was greater than that of the ligand. The experiment was repeated three times using the same procedure conditions. The Co (II)
Bacillus cereus and Mn (II) complex showed week antibacterial property against Escherichia coli.

\section{Acknowledgements}

This research paper is retrieved from Miss Fatemeh Dashti Rahmatabadi thesis. Authors would like to thank Tehran North Branch, Islamic Azad University research council for its financial support.

\section{References}

[1] A. Xavier, N. Srividhy, J. Appl. Chem, 2014, 7, 6-15.

[2] I. Sheikhshoaiea, M. Sheikhshoaie, S. Ramezanpour, Chem. Methodol., 2018, 2, 103113. 
[3] P. Parimal, J. Chem. Sci., 2002, 114, 269276.

[4] A. Malek, G.C. Dey, A. Nasreen, T.A. Chowdhury, E.C. Alyea, Synth. React. Inorg. Met.-Org. Chem., 1979, 9, 145-155.

[5] D.F. Cook, D. Cummins, E.D. McKenzie, J. Chem. Soc., Dalton Trans, 1976, 1369-1375.

[6] E.C. Brown, B. Johnson, S. Palavicini, B. Kucera, L. Casella, W.B. Tolman, Dalton Trans., 2007, 3035-3042.

[7] G.A. McLachlan, G.D. Fallon, L. Spiccia, Acta Crystallogr. Sect. C: Cryst. Struct. Commun., 1996, 52, 309- 312.

[8] A. Smith, S.J. Retting, C. Orvig, Inorg. Chem, 1988, 27, 3929-3934.

[9] S. Mizukami, H. Houjou, M. Kanesato, K. Hiratani, Chemistry-A, 2003, 9, 1521-1528.

[10] L.W. Yang, Sh. Liu, S.J. Retting, Ch. Orvig, Inorg. Chem., 1995, 34, 4921-4925.

[11] A. Deroche, I.M. Badarau, M. Cesario, J. Guilhem, B. Keita, L. Nadjo, C.H. Levin, J. Am. Chem. Soc., 1996, 118, 4567-4573.

[12] L.J. Wilson, N.J. Rose, J. Am. Chem. Soc., 1968, 90, 6041-6045.

[13] R.M. Kirchner, C. Mealli, M. Bailey, N. Howe, L.P. Torr, L.J. Wilson, L.C. Andrews, N.J. Rose, E.C. Lingafelter, Coord. Chem. Rev., 1987, 77, 89-163.

[14] Y. Elerman, M. Kabak, I. Svoboda, M. Geselle, Acta Crystallogr., Sect. C: Struct. Chem., 1994, 50, 1694- 1696.

[15] T.D. Karpishin, T.D.P. Stack, K.N. Raymond, J. Am. Chem. Soc., 1993, 115, 61156125.

[16] G. Barre, D. Taton, D. Lastecoueres, J. Vincent, J. Am. Chem. Soc., 2004, 126, 77647765.

[17] Y. Wang, T. Liang, J. Yao, T. Zhai. H. Fu, Acta Crystallogr. Sect. E: Struct. Rep., 2008, 64, 0629.

[18] P. Greig. Sim, E. Sinn, Inorg. Chem., 1978, 17, 1288-1290.

[19] M. Yilmaz, M. Sahin, N. Kocak, U. Sayin, J. Macromol. Sci., Part A: Pure Appl. Chem., 2012, 49, 603-610.

[20] K. Wai-Yan. Chan, S. Barra, M. Botta, W. Wong, J. Inorg Biochem., 2004, 98, 677-82.
[21] S. Liu, D. Scott Edwards, Bioconjugate Chem., 2001, 12, 7-34.

[22] S. Tamburini, P.A. Vigato, M. Gatos, L. Bertolo, U. Casellato, Inorg. Chim. Acta., 2006, 359, 183-196.

[23] X. Wang, X. Xie, Y. Cai, X.X. Yang, J. Li, Y. Li, W. Chen, M. He, Molecules, 2016, 21, 340344.

[24] N.S. Gwaram, H. Mohd Ali, S.M. Saharin, H. Khaledi, M.A. Abdulla, Th. K. Lin, Ch.L. Ching, Ch.L. Ooi, J. Appl. Pharm. Sci., 2013, 2, 27-38.

[25] M. Badea, A. Emandi, D. Marinescu, E. Cristurean, R. Olar, A. Braileanu, P. Budrugeac, E. Segal, J. Therm. Anal. Calorim., 2003, 72, 525-531.

[26] J.W. Searl, R.C. Smith, S.J. Wyard, Proc. Phys. Soc., 1961, 78, 1174-1176.

[27] Y. Anjaneyula, R. Prabhakara Rao, Synth. React. Inorg. Met-Org. Chem., 1986, 16, 257272.

[28] K.S. Prasad, L.S. Kumar, S.C. Shekar, M. Prasad, H.D. Revanasiddappa, Chem. Sci. J., 2011, 12, 1-10.

How to cite this article: Fatemeh Dashti Rahmatabadi, Roya Ranjineh Khojasteh*, Hassan Kabiri Fard, Fariba Tadayon. Synthesis, characterization, and antibacterial activities of some metal complexes with tripodal Schiff base ligand derived from pyrrole-2-carboxaldehyde. Eurasian Chemical Communications, 2020, 2(5), 587-594. Link: http://www.echemcom.com/article_10174 3.html 